CUBO A Mathematical Journal Vol.16, № 01, (09-20). March 2014

\title{
Viscosity approximation methods with a sequence of contractions
}

\author{
KoJI AOYAMa $\dagger$ \\ Department of Economics, \\ Chiba University, \\ Yayoi-cho, Inage-ku, Chiba-shi, Chiba \\ 263-8522, Japan. \\ aoyama@le.chiba-u.ac.jp
}

\author{
YASUNORI KIMURA $\ddagger$ \\ Department of Information Science, \\ Toho University, \\ Miyama, Funabashi, Chiba 274-8510, Japan. \\ yasunori@is.sci. toho-u.ac.jp
}

\begin{abstract}
The aim of this paper is to prove that, in an appropriate setting, every iterative sequence generated by the viscosity approximation method with a sequence of contractions is convergent whenever so is every iterative sequence generated by the Halpern type iterative method. Then, using our results, we show some convergence theorems for variational inequality problems, zero point problems, and fixed point problems.
\end{abstract}

\section{RESUMEN}

La meta de este artículo es probar en un marco de trabajo adecuado que cada sucesión iterativa generada por el método de aproximación de viscosidad con una sucesión cualquiera de contracciones es convergente como lo es cada sucesión iterativa generada por el método iterativo del tipo Halpern. Así, usando nuestro resultado mostramos algunos teoremas de convergencia para problemas de desigualdades variacionales, problemas de punto cero y problemas de punto fijo.

Keywords and Phrases: Viscosity approximation method, nonexpansive mapping, fixed point, hybrid steepest descent method.

2010 AMS Mathematics Subject Classification: 47H09, 47J20, 47H10. 


\section{Introduction}

Let $\mathrm{C}$ be a nonempty closed convex subset of a Hilbert space. This paper is devoted to the study of strong convergence of a sequence $\left\{y_{n}\right\}$ in $C$ defined by an arbitrary point $y_{1} \in C$ and

$$
y_{n+1}=\lambda_{n} f_{n}\left(y_{n}\right)+\left(1-\lambda_{n}\right) T_{n} y_{n}
$$

for $n \in \mathbb{N}$, where $\lambda_{n}$ is a real number in $[0,1], f_{n}$ is a contraction on $C$, and $T_{n}$ is a nonexpansive mapping on $C$ for $n \in \mathbb{N}$. In particular, our main interest is the relationship between convergence of such a sequence $\left\{y_{n}\right\}$ and a sequence $\left\{x_{n}\right\}$ defined by an arbitrary point $x_{1} \in C$ and

$$
x_{n+1}=\lambda_{n} u+\left(1-\lambda_{n}\right) T_{n} x_{n}
$$

for $n \in \mathbb{N}$, where $u$ is a point in C. In $\S 3$, using the technique developed in [21], we prove that their convergence are equivalent under some assumptions. Then, as applications of our convergence results in $\S 3$, we discuss strong convergence of the sequences generated by the hybrid steepest descent method [30] and we give another proof of Iemoto and Takahashi's theorem [17] in $\S 4$. Moreover, we show one generalization of Ceng, Petrusel, and Yao's theorem [13] in §5.

The iterative method defined by (1.1) is based on the viscosity approximation method due to Moudafi [19]. He considered the fixed point problem of a single nonexpansive mapping and proved strong convergence of sequences generated by the viscosity approximation methods; see also Xu [28] and Suzuki [21].

The iterative method defined by (1.2) is called the Halpern type iterative method; see Halpern [16], Wittmann [25], and Shioji and Takahashi [20]; see also [1,5,7].

\section{Preliminaries}

Throughout the present paper, $\mathrm{H}$ denotes a real Hilbert space with the inner product $\langle\cdot, \cdot\rangle$ and the norm $\|\cdot\|, \mathrm{C}$ a nonempty closed convex subset of $\mathrm{H}$, I the identity mapping on $\mathrm{H}$, and $\mathbb{N}$ the set of positive integers.

A mapping $S: C \rightarrow H$ is said to be lipschitzian if there exists a constant $\eta \geq 0$ such that $\|S x-S y\| \leq \eta\|x-y\|$ for all $x, y \in C$. In this case, $S$ is called an $\eta$-lipschitzian mapping. In particular, an $\eta$-lipschitzian mapping is said to be nonexpansive if $\eta=1$; an $\eta$-lipschitzian mapping is said to be an $\eta$-contraction if $0 \leq \eta<1$. It is known that $\operatorname{Fix}(S)$ is closed and convex if $S$ : $C \rightarrow H$ is nonexpansive, where $\operatorname{Fix}(\mathrm{S})$ denotes the set of fixed points of $\mathrm{S}$. The metric projection of $\mathrm{H}$ onto $\mathrm{C}$ is denoted by $\mathrm{P}_{\mathrm{C}}$ and we know that $\mathrm{P}_{\mathrm{C}}$ is nonexpansive. We also know the following; see [22].

Lemma 2.1. Let $\mathrm{x} \in \mathrm{H}$ and $z \in \mathrm{C}$. Then $z=\mathrm{P}_{\mathrm{C}}(\mathrm{x})$ if and only if $\langle\mathrm{y}-z, \mathrm{x}-z\rangle \leq 0$ for all $\mathrm{y} \in \mathrm{C}$.

Let $\left\{S_{n}\right\}$ be a sequence of nonexpansive mappings of $C$ into $H$. We say that $\left\{S_{n}\right\}$ satisfies the condition (Z) if every weak cluster point of $\left\{x_{n}\right\}$ is a common fixed point of $\left\{S_{n}\right\}$ whenever $\left\{x_{n}\right\}$ 
is a bounded sequence in $C$ and $x_{n}-S_{n} x_{n} \rightarrow 0$; see $[1,3,8-11]$. We say that $\left\{S_{n}\right\}$ satisfies the condition $(R)$ if

$$
\lim _{n \rightarrow \infty} \sup _{y \in D}\left\|S_{n+1} y-S_{n} y\right\|=0
$$

for every nonempty bounded subset $\mathrm{D}$ of $\mathrm{C}$; see $[1,5]$. We say that $\left\{\mathrm{S}_{\mathrm{n}}\right\}$ is stable on a nonempty subset $\mathrm{D}$ of $\mathrm{C}$ if $\left\{S_{n} z: n \in \mathbb{N}\right\}$ is a singleton for every $z \in D$.

We need the following lemmas:

Lemma 2.2. Let $\mathrm{C}_{1}$ and $\mathrm{C}_{2}$ be nonempty closed convex subsets of $\mathrm{H},\left\{\mathrm{S}_{\mathrm{n}}\right\}$ a sequence of nonexpansive mappings of $\mathrm{C}_{1}$ into $\mathrm{H}$, and $\left\{\mathrm{T}_{\mathrm{n}}\right\}$ a sequence of nonexpansive mappings of $\mathrm{C}_{2}$ into $\mathrm{H}$. Suppose that $\left\{\mathrm{S}_{\mathrm{n}}\right\}$ and $\left\{\mathrm{T}_{\mathrm{n}}\right\}$ satisfy the condition $(R), \mathrm{C}_{1} \supset \mathrm{T}_{\mathrm{n}}\left(\mathrm{C}_{2}\right)$ for every $\mathrm{n} \in \mathbb{N}$, and $\left\{\mathrm{T}_{\mathrm{n}}\right\}$ has a common fixed point. Then $\left\{\mathrm{S}_{\mathrm{n}} \mathrm{T}_{\mathrm{n}}\right\}$ satisfies the condition $(R)$.

Proof. Let $\mathrm{D}$ be a nonempty bounded subset of $\mathrm{C}_{2}$. Then it is clear that each $\mathrm{S}_{\mathrm{n}} \mathrm{T}_{\mathrm{n}}$ is nonexpansive and

$$
\begin{aligned}
\left\|S_{n+1} T_{n+1} y-S_{n} T_{n} y\right\| & \leq\left\|S_{n+1} T_{n+1} y-S_{n} T_{n+1} y\right\|+\left\|S_{n} T_{n+1} y-S_{n} T_{n} y\right\| \\
& \leq\left\|S_{n+1} T_{n+1} y-S_{n} T_{n+1} y\right\|+\left\|T_{n+1} y-T_{n} y\right\|
\end{aligned}
$$

for all $y \in D$ and $n \in \mathbb{N}$. Let $z$ be a common fixed point of $\left\{T_{n}\right\}$. Then it is obvious that

$$
\left\|\mathrm{T}_{\mathrm{n}} \mathrm{y}\right\| \leq\left\|\mathrm{T}_{\mathrm{n}} \mathrm{y}-\mathrm{T}_{\mathrm{n}} z\right\|+\|z\| \leq\|\mathrm{y}-z\|+\|z\|
$$

for all $y \in D$ and $n \in \mathbb{N}$. This shows that $D^{\prime}=\left\{T_{n} y: n \in \mathbb{N}, y \in D\right\}$ is a bounded subset of $C_{1}$. Since $\left\{S_{n}\right\}$ and $\left\{T_{n}\right\}$ satisfy the condition $(R)$, it follows from (2.1) that

$$
\sup _{y \in D}\left\|S_{n+1} T_{n+1} y-S_{n} T_{n} y\right\| \leq \sup _{y^{\prime} \in D^{\prime}}\left\|S_{n+1} y^{\prime}-S_{n} y^{\prime}\right\|+\sup _{y \in D}\left\|T_{n+1} y-T_{n} y\right\| \rightarrow 0 .
$$

Therefore, $\left\{S_{n} T_{n}\right\}$ satisfies the condition $(R)$.

Lemma 2.3. Let $\left\{\mathrm{S}_{\mathrm{n}}\right\}$ be a sequence of nonexpansive mappings of $\mathrm{C}$ into $\mathrm{H}$ and $\left\{\gamma_{\mathrm{n}}\right\}$ a sequence in $[0,1]$ such that $\gamma_{n+1}-\gamma_{n} \rightarrow 0$. Suppose that $\left\{S_{n}\right\}$ satisfies the condition $(R)$ and $\left\{S_{n}\right\}$ has a common fixed point. Then $\left\{\gamma_{n} \mathrm{I}+\left(1-\gamma_{n}\right) S_{n}\right\}$ satisfies the condition $(R)$.

Proof. Set $U_{n}=\gamma_{n} I+\left(1-\gamma_{n}\right) S_{n}$ for $n \in \mathbb{N}$. Let $D$ be a nonempty bounded subset of $C$. Then it is clear that each $\mathrm{U}_{\mathrm{n}}$ is nonexpansive and

$$
\begin{aligned}
\left\|u_{n+1} y-u_{n} y\right\| & \leq\left|\gamma_{n+1}-\gamma_{n}\right|\left\|y-S_{n} y\right\|+\left|1-\gamma_{n+1}\right|\left\|S_{n+1} y-S_{n} y\right\| \\
& \leq\left|\gamma_{n+1}-\gamma_{n}\right|\left\|y-S_{n} y\right\|+\left\|S_{n+1} y-S_{n} y\right\|
\end{aligned}
$$

for all $y \in D$ and $n \in \mathbb{N}$. Let $z$ be a common fixed point of $\left\{S_{n}\right\}$. Then it is obvious that

$$
\left\|y-S_{n} y\right\| \leq\|y-z\|+\left\|S_{n} z-S_{n} y\right\| \leq 2\|y-z\|
$$


for all $y \in D$ and $n \in \mathbb{N}$. Since $\left\{S_{n}\right\}$ satisfies the condition $(R)$ and $\gamma_{n+1}-\gamma_{n} \rightarrow 0$, it follows from (2.2) and (2.3) that

$$
\sup _{y \in D}\left\|U_{n+1} y-U_{n} y\right\| \leq 2\left|\gamma_{n+1}-\gamma_{n}\right|\|y-z\|+\sup _{y \in D}\left\|S_{n+1} y-S_{n} y\right\| \rightarrow 0 .
$$

Therefore, $\left\{\mathrm{U}_{\mathrm{n}}\right\}$ satisfies the condition $(\mathrm{R})$.

A set-valued mapping $A$ of $H$ into $H$, which is denoted by $A \subset \mathrm{H} \times \mathrm{H}$, is said to be a monotone operator if $\left\langle x-y, x^{\prime}-y^{\prime}\right\rangle \geq 0$ for all $\left(x, x^{\prime}\right),\left(y, y^{\prime}\right) \in A$. A monotone operator $A \subset H \times H$ is said to be maximal if $A=B$ whenever $B \subset H \times H$ is a monotone operator such that $A \subset B$. Let $A \subset H \times H$ be a maximal monotone operator. It is known that $(I+\rho A)^{-1}$ is a single-valued mapping of $H$ onto $\operatorname{dom}(A)=\{x \in H: A x \neq \emptyset\}$ for all $\rho>0$. Such a mapping $(I+\rho A)^{-1}$ is called the resolvent of $A$ and denoted by $J_{\rho}$. It is also known that the resolvent $J_{\rho}$ is nonexpansive and $\operatorname{Fix}\left(J_{\rho}\right)=A^{-1} 0=\{x \in H: A x \ni 0\}$; see [22] for more details.

A mapping $\mathrm{A}: \mathrm{H} \rightarrow \mathrm{H}$ is said to be strongly monotone if there is a constant $\mathrm{k}>0$ such that $\langle x-y, A x-A y\rangle \geq \kappa\|x-y\|^{2}$ for all $x, y \in H$. In this case, $A$ is called a $k$-strongly monotone mapping. The following lemma is well known; see, for example, [4].

Lemma 2.4. Let $\mathrm{K}$ and $\eta$ be positive real numbers such that $\eta^{2}<2 \kappa$. Let $\mathrm{F}$ be a nonempty closed convex subset of $\mathrm{H}$ and $\mathrm{A}: \mathrm{H} \rightarrow \mathrm{H}$ a $\mathrm{k}$-strongly monotone and $\eta$-lipschitzian mapping. Then the following hold:

(1) $\mathrm{K} \leq \eta, 0 \leq 1-2 \kappa+\eta^{2}<1$ and $\mathrm{I}-\mathrm{A}$ is a $\theta$-contraction, where $\theta=\sqrt{1-2 \kappa+\eta^{2}}$.

(2) There exists a unique point $z \in \mathrm{F}$ such that $\langle\mathrm{y}-z, \mathrm{~A} z\rangle \geq 0$ for all $\mathrm{y} \in \mathrm{F}$, and moreover, $z$ is the unique fixed point of $\mathrm{P}_{\mathrm{F}}(\mathrm{I}-\mathrm{A})$.

The following lemma is well known; see [7,18,24,26,27].

Lemma 2.5. Let $\left\{\epsilon_{n}\right\}$ be a sequence of nonnegative real numbers, $\left\{\gamma_{n}\right\}$ a sequence of real numbers, and $\left\{\lambda_{n}\right\}$ a sequence in $[0,1]$. Suppose that $\epsilon_{n+1} \leq\left(1-\lambda_{n}\right) \epsilon_{n}+\lambda_{n} \gamma_{n}$ for every $n \in \mathbb{N}$, $\lim \sup _{n \rightarrow \infty} \gamma_{n} \leq 0$, and $\sum_{n=1}^{\infty} \lambda_{n}=\infty$. Then $\epsilon_{n} \rightarrow 0$.

\section{Viscosity approximation method with a sequence of con- tractions}

In this section, we deal with the viscosity approximation method due to Moudafi [19] in order to find a common fixed point of a sequence of nonexpansive mappings. In particular, we focus on the viscosity approximation method with a sequence of contractions. We first investigate the relationship between this method and the Halpern type iterative method (Theorem 3.1). Then, by using known results (Theorems 3.3 and 3.5), we show convergence theorems (Theorems 3.4 and $3.6)$. 
Using the technique in [21], we can prove the following:

Theorem 3.1. Let $\mathrm{H}$ be a Hilbert space, $\mathrm{C}$ a nonempty closed convex subset of $\mathrm{H},\left\{\mathrm{T}_{\mathrm{n}}\right\}$ a sequence of nonexpansive self-mappings of $\mathrm{C}, \mathrm{F}$ a nonempty closed convex subset of $\mathrm{C}, \theta$ a nonnegative real number with $\theta<1$, and $\left\{\lambda_{n}\right\}$ a sequence in $[0,1]$ such that $\sum_{n=1}^{\infty} \lambda_{n}=\infty$. Then the following are equivalent:

(1) For any $(\mathrm{x}, \mathrm{u}) \in \mathrm{C} \times \mathrm{C}$, the sequence $\left\{\mathrm{x}_{\mathrm{n}}\right\}$ defined by $\mathrm{x}_{1}=\mathrm{x}$ and

$$
x_{n+1}=\lambda_{n} u+\left(1-\lambda_{n}\right) T_{n} x_{n}
$$

for $\mathrm{n} \in \mathbb{N}$ converges strongly to $\mathrm{P}_{\mathrm{F}}(\mathrm{u})$.

(2) For any $\mathrm{y} \in \mathrm{C}$ and any sequence $\left\{\mathrm{f}_{\mathrm{n}}\right\}$ of $\theta$-contractions on $\mathrm{C}$ which is stable on $\mathrm{F}$, the sequence $\left\{\mathrm{y}_{\mathrm{n}}\right\}$ defined by $\mathrm{y}_{1}=\mathrm{y}$ and

$$
y_{n+1}=\lambda_{n} f_{n}\left(y_{n}\right)+\left(1-\lambda_{n}\right) T_{n} y_{n}
$$

for $\mathrm{n} \in \mathbb{N}$ converges strongly to $\boldsymbol{w}$, where $\boldsymbol{w}$ is the unique fixed point of $\mathrm{P}_{\mathrm{F}} \circ \mathrm{f}_{1}$.

Proof. We first show that (1) implies (2). Let $\left\{f_{n}\right\}$ be a sequence of $\theta$-contractions on $C$ which is stable on $F, w$ the fixed point of a contraction $P_{F} \circ f_{1}$, and $y \in C$. Let $\left\{x_{n}\right\}$ be a sequence defined by $x_{1}=y$ and

$$
x_{n+1}=\lambda_{n} f_{1}(w)+\left(1-\lambda_{n}\right) T_{n} x_{n}
$$

for $\mathrm{n} \in \mathbb{N}$. Then $x_{n} \rightarrow P_{F}\left(f_{1}(w)\right)=w$ by (1). Since $T_{n}$ is nonexpansive and $f_{n}$ is a $\theta$-contraction, it follows from $f_{1}(w)=f_{n}(w)$ that

$$
\begin{aligned}
\left\|x_{n+1}-y_{n+1}\right\| & =\left\|\left(1-\lambda_{n}\right)\left(T_{n} x_{n}-T_{n} y_{n}\right)+\lambda_{n}\left(f_{1}(w)-f_{n}\left(y_{n}\right)\right)\right\| \\
& \leq\left(1-\lambda_{n}\right)\left\|T_{n} x_{n}-T_{n} y_{n}\right\|+\lambda_{n}\left\|f_{n}(w)-f_{n}\left(y_{n}\right)\right\| \\
& \leq\left(1-\lambda_{n}\right)\left\|x_{n}-y_{n}\right\|+\lambda_{n} \theta\left\|w-y_{n}\right\| \\
& \leq\left(1-\lambda_{n}\right)\left\|x_{n}-y_{n}\right\|+\lambda_{n} \theta\left(\left\|w-x_{n}\right\|+\left\|x_{n}-y_{n}\right\|\right) \\
& \leq\left(1-(1-\theta) \lambda_{n}\right)\left\|x_{n}-y_{n}\right\|+(1-\theta) \lambda_{n} \frac{\theta}{1-\theta}\left\|x_{n}-w\right\|
\end{aligned}
$$

for every $n \in \mathbb{N}$. Since $\sum_{n=1}^{\infty}(1-\theta) \lambda_{n}=\infty$ and $x_{n} \rightarrow w$, Lemma 2.5 shows that $x_{n}-y_{n} \rightarrow 0$. Therefore, we conclude that $y_{n} \rightarrow w$.

We next show that (2) implies (1). Let $(x, \mathfrak{u}) \in \mathrm{C} \times \mathrm{C}$ be given. For each $n \in \mathbb{N}$, let $f_{n}$ be a mapping defined by $f_{n}(z)=u$ for $z \in C$. Then, obviously, each $f_{n}$ is a 0-contraction and $\left\{f_{n}\right\}$ is stable on $\mathrm{F}$. Thus it follows from (2) that $\left\{x_{n}\right\}$ converges strongly to $w=P_{F}\left(f_{1}(w)\right)=P_{F}(u)$.

Remark 3.2. It is easy to check that Theorem 3.1 holds even if $\mathrm{H}$ is a Banach space under appropriate conditions.

We know the following result; see $[2,7]$ and see also $[3,11]$. 
Theorem 3.3. Let $\mathrm{H}$ be a Hilbert space, $\mathrm{C}$ a nonempty closed convex subset of $\mathrm{H},\left\{\mathrm{T}_{\mathrm{n}}\right\}$ a sequence of nonexpansive self-mappings of $\mathrm{C}$ with a common fixed point, $\mathrm{F}$ the set of common fixed points of $\left\{\mathrm{T}_{n}\right\}$, and $\left\{\lambda_{n}\right\}$ a sequence in $[0,1]$ such that

$$
\lambda_{n} \rightarrow 0, \sum_{n=1}^{\infty} \lambda_{n}=\infty, \text { and } \sum_{n=1}^{\infty}\left|\lambda_{n+1}-\lambda_{n}\right|<\infty .
$$

Suppose that $\left\{\mathrm{T}_{\mathrm{n}}\right\}$ satisfies the condition $(Z)$ and

$$
\sum_{n=1}^{\infty} \sup \left\{\left\|T_{n+1} y-T_{n} y\right\|: y \in D\right\}<\infty
$$

for every nonempty bounded subset $\mathrm{D}$ of $\mathrm{C}$. Let $\mathrm{x}$ and $\mathrm{u}$ be points in $\mathrm{C}$ and $\left\{\mathrm{x}_{\mathrm{n}}\right\}$ a sequence defined by $\mathrm{x}_{1}=\mathrm{x}$ and (3.1) for $\mathrm{n} \in \mathbb{N}$. Then $\left\{\mathrm{x}_{\mathfrak{n}}\right\}$ converges strongly to $\mathrm{P}_{\mathrm{F}}(\mathrm{u})$.

Using Theorems 3.1 and 3.3, we obtain the following:

Theorem 3.4. Let $\mathrm{H}, \mathrm{C},\left\{\mathrm{T}_{\mathrm{n}}\right\}, \mathrm{F}$, and $\left\{\lambda_{\mathrm{n}}\right\}$ be the same as in Theorem 3.3. Let $\theta$ be a nonnegative real number with $\theta<1$ and $\left\{\mathrm{f}_{\mathrm{n}}\right\}$ a sequence of $\theta$-contractions on $\mathrm{C}$ which is stable on $\mathrm{F}$. Let $\mathrm{y}$ be a point in $\mathrm{C}$ and $\left\{\mathrm{y}_{\mathrm{n}}\right\}$ a sequence defined by $\mathrm{y}_{1}=\mathrm{y}$ and (3.2) for $\mathrm{n} \in \mathbb{N}$. Then $\left\{\mathrm{y}_{\mathrm{n}}\right\}$ converges strongly to $w$, where $w$ is the unique fixed point of $\mathrm{P}_{\mathrm{F}} \circ \mathrm{f}_{1}$.

We also know the following result; see $[1,5]$.

Theorem 3.5. Let $\mathrm{H}$ be a Hilbert space, $\mathrm{C}$ a nonempty closed convex subset of $\mathrm{H},\left\{\mathrm{S}_{\mathrm{n}}\right\}$ a sequence of nonexpansive self-mappings of $\mathrm{C}$ with a common fixed point, $\mathrm{F}$ the set of common fixed points of $\left\{S_{n}\right\}$. Let $\left\{\lambda_{n}\right\}$ and $\left\{\beta_{n}\right\}$ be sequences in $[0,1]$ such that

$$
\lambda_{n} \rightarrow 0, \sum_{n=1}^{\infty} \lambda_{n}=\infty \text {, and } 0<\liminf _{n \rightarrow \infty} \beta_{n} \leq \limsup _{n \rightarrow \infty} \beta_{n}<1 \text {. }
$$

Suppose that $\left\{\mathrm{S}_{\mathrm{n}}\right\}$ satisfies the conditions $(Z)$ and $(R)$. Let $\mathrm{x}$ and $\mathrm{u}$ be points in $\mathrm{C}$ and $\left\{\mathrm{x}_{\mathrm{n}}\right\}$ a sequence defined by $\mathrm{x}_{1}=\mathrm{x}$ and

$$
x_{n+1}=\lambda_{n} u+\left(1-\lambda_{n}\right)\left(\left(1-\beta_{n}\right) x_{n}+\beta_{n} S_{n} x_{n}\right)
$$

for $\mathrm{n} \in \mathbb{N}$. Then $\left\{x_{n}\right\}$ converges strongly to $\mathrm{P}_{\mathrm{F}}(\mathrm{u})$.

Using Theorems 3.1 and 3.5 , we also obtain the following:

Theorem 3.6. Let $\mathrm{H}, \mathrm{C},\left\{\mathrm{S}_{\mathrm{n}}\right\}, \mathrm{F},\left\{\lambda_{\mathrm{n}}\right\}$, and $\left\{\beta_{\mathrm{n}}\right\}$ be the same as in Theorem 3.5. Let $\theta$ be a nonnegative real number with $\theta<1$ and $\left\{\mathrm{f}_{\mathrm{n}}\right\}$ a sequence of $\theta$-contractions on $\mathrm{C}$ which is stable on F. Let $\mathrm{y}$ be a point in $\mathrm{C}$ and $\left\{\mathrm{y}_{\mathrm{n}}\right\}$ a sequence defined by $\mathrm{y}_{1}=\mathrm{y}$ and

$$
y_{n+1}=\lambda_{n} f_{n}\left(y_{n}\right)+\left(1-\lambda_{n}\right)\left(\left(1-\beta_{n}\right) y_{n}+\beta_{n} S_{n} y_{n}\right)
$$

for $\mathrm{n} \in \mathbb{N}$. Then $\left\{\mathrm{y}_{\mathrm{n}}\right\}$ converges strongly to $\mathrm{w}$, where $\mathrm{w}$ is the unique fixed point of $\mathrm{P}_{\mathrm{F}} \circ \mathrm{f}_{1}$. 
Proof. Set $T_{n}=\left(1-\beta_{n}\right) I+\beta_{n} S_{n}$ for $n \in \mathbb{N}$. Then it is clear that each $T_{n}$ is nonexpansive and $y_{n+1}=\lambda_{n} f_{n}\left(y_{n}\right)+\left(1-\lambda_{n}\right) T_{n} y_{n}$ for $n \in \mathbb{N}$. Let $x$ and $u$ be points in $C$ and $\left\{x_{n}\right\}$ a sequence defined by $x_{1}=x$ and $x_{n+1}=\lambda_{n} u+\left(1-\lambda_{n}\right) T_{n} x_{n}$ for $n \in \mathbb{N}$. Then it follows from Theorem 3.5 that $x_{n} \rightarrow P_{F}(u)$. Therefore, Theorem 3.1 implies the conclusion.

\section{Convergence theorems by the hybrid steepest descent method}

In this section, we deal with the variational inequality problem over the set of common fixed points of a sequence of nonexpansive mappings; see Problem 4.1 below. Then we prove some strong convergence theorems by the hybrid steepest descent method introduced by Yamada [30]. We know many results by using the hybrid steepest descent method; see $[2,14,17,29,31]$.

Problem 4.1. Let $\mathrm{H}$ be a Hilbert space, $\left\{\mathrm{T}_{\mathrm{n}}\right\}$ a sequence of nonexpansive self-mappings of $\mathrm{H}$ with a common fixed point, $\mathrm{F}$ the set of common fixed points of $\left\{\mathrm{T}_{\mathrm{n}}\right\}$, and $\mathrm{A}: \mathrm{H} \rightarrow \mathrm{H}$ a $\mathrm{K}$-strongly monotone and $\eta$-lipschitzian mapping, where $\mathrm{\kappa}$ and $\eta$ are positive real numbers such that $\eta^{2}<2 \mathrm{\kappa}$. Then find $z \in \mathrm{F}$ such that

$$
\langle y-z, A z\rangle \geq 0 \text { for all } y \in F .
$$

Remark 4.2. The assumption that $\eta^{2}<2 \kappa$ in Problem 4.1 is not restrictive. Indeed, suppose that a $\mathrm{k}$-strongly monotone and $\eta$-lipschitzian mapping $\mathrm{A}$ is given. Let us choose a positive constant $\mu$ such that $\mu<2 \kappa / \eta^{2}$, and define $\kappa^{\prime}=\mu \kappa$ and $\eta^{\prime}=\mu \eta$. Then it is easy to verify that $\left(\eta^{\prime}\right)^{2}<2 \kappa^{\prime}$, $\mu \mathrm{A}$ is $\mathrm{K}^{\prime}$-strongly monotone and $\eta^{\prime}$-lipschitzian, and moreover, $\langle\mathrm{y}-z, \mathrm{Az}\rangle \geq 0$ is equivalent to $\langle\mathrm{y}-z, \mu \mathrm{A} z\rangle \geq 0$ for every $\mathrm{y}, z \in \mathrm{H}$.

As a consequence of Theorem 3.1, we can obtain the following theorem, which shows that every sequence generated by the hybrid steepest descent method for Problem 4.1 is convergent whenever so is every sequence generated by the Halpern type iterative method for the sequence of nonexpansive mappings.

Theorem 4.3. Let $\mathrm{H},\left\{\mathrm{T}_{\mathrm{n}}\right\}, \mathrm{F}, \mathrm{\kappa}, \mathrm{\eta}$, and $\mathrm{A}$ be the same as in Problem 4.1. Let $\left\{\lambda_{\mathrm{n}}\right\}$ be a sequence in $[0,1]$ such that $\sum_{n=1}^{\infty} \lambda_{n}=\infty$. Suppose that for any $(x, u) \in \mathrm{H} \times \mathrm{H}$, the sequence $\left\{x_{n}\right\}$ defined by $\mathrm{x}_{1}=\mathrm{x}$ and

$$
x_{n+1}=\lambda_{n} u+\left(1-\lambda_{n}\right) T_{n} x_{n}
$$

for $\mathrm{n} \in \mathbb{N}$ converges strongly to $\mathrm{P}_{\mathrm{F}}(\mathrm{u})$. Let $\mathrm{y}$ be a point in $\mathrm{H}$ and $\left\{\mathrm{y}_{\mathrm{n}}\right\}$ a sequence defined by $\mathrm{y}_{1}=\mathrm{y}$ and

$$
y_{n+1}=\left(I-\lambda_{n} A\right) T_{n} y_{n}
$$

for $\mathrm{n} \in \mathbb{N}$. Then $\left\{\mathrm{y}_{\mathrm{n}}\right\}$ converges strongly to the unique solution of Problem 4.1. 
Proof. Set $f_{n}=(I-A) T_{n}$ for $n \in \mathbb{N}$. Since $T_{n}$ is nonexpansive, $f_{n}$ is a $\theta$-contraction by Lemma 2.4 , where $\theta=\sqrt{1-2 \kappa+\eta^{2}}$. By the definition of $\left\{y_{n}\right\}$, it is clear that

$$
y_{n+1}=\lambda_{n}(I-A) T_{n} x_{n}+\left(1-\lambda_{n}\right) T_{n} y_{n}=\lambda_{n} f_{n}\left(y_{n}\right)+\left(1-\lambda_{n}\right) T_{n} y_{n}
$$

for every $n \in \mathbb{N}$. It is also clear that $\left\{f_{n}\right\}$ is stable on $F$. Thus Theorem 3.1 implies that $\left\{y_{n}\right\}$ converges strongly to $w=\mathrm{P}_{\mathrm{F}}\left((\mathrm{I}-\mathrm{A}) \mathrm{T}_{1} w\right)=\mathrm{P}_{\mathrm{F}}(\mathrm{I}-\mathrm{A}) \mathrm{w}$, which is the unique solution of Problem 4.1 by Lemma 2.4 .

Using Theorem 3.6 and other known results, we also obtain the following:

Theorem 4.4 (Iemoto and Takahashi [17, Theorem 3.1]). Let $\mathrm{H},\left\{\mathrm{T}_{\mathrm{n}}\right\}, \mathrm{F}, \mathrm{\kappa}, \mathrm{\eta}$, and $\mathrm{A}$ be the same as in Problem 4.1. Let $\left\{\lambda_{\mathrm{n}}\right\}$ be a sequence in $[0,1]$ such that

$$
\lambda_{n} \rightarrow 0 \text { and } \sum_{n=1}^{\infty} \lambda_{n}=\infty
$$

and $\left\{\gamma_{\mathrm{n}}\right\}$ a sequence in $[\mathrm{a}, \mathrm{b}]$, where $0<\mathrm{a} \leq \mathrm{b}<1$. For each $\mathrm{n} \in \mathbb{N}$ and $\mathrm{k} \in\{1,2, \ldots, \mathrm{n}+1\}$, let $\mathrm{U}_{\mathrm{n}, \mathrm{k}}$ be a mapping defined by

$$
\mathrm{U}_{\mathrm{n}, \mathrm{k}}= \begin{cases}\mathrm{I} & \text { if } \mathrm{k}=\mathrm{n}+1 \\ \mathrm{U}_{\mathrm{n}, \mathrm{k}}=\left(1-\gamma_{\mathrm{k}}\right) \mathrm{I}+\gamma_{\mathrm{k}} \mathrm{T}_{\mathrm{k}} \mathrm{U}_{\mathrm{n}, \mathrm{k}+1} & \text { if } \mathrm{k} \in\{1,2, \ldots, \mathrm{n}\} .\end{cases}
$$

Let $\mathrm{y}$ be a point in $\mathrm{H}$ and $\left\{\mathrm{y}_{\mathrm{n}}\right\}$ a sequence defined by $\mathrm{y}_{1}=\mathrm{y}$ and

$$
y_{n+1}=\left(I-\lambda_{n} A\right) U_{n, 1} y_{n}
$$

for $\mathrm{n} \in \mathbb{N}$. Then $\left\{\mathrm{y}_{\mathrm{n}}\right\}$ converges strongly to the unique solution of Problem 4.1.

Proof. Set $f_{n}=(I-A) U_{n, 1}$ and $S_{n}=T_{1} U_{n, 2}$ for $n \in \mathbb{N}$. Then it is obvious from (4.3) that

$$
\begin{aligned}
y_{n+1} & =\lambda_{n}(I-A) U_{n, 1} y_{n}+\left(1-\lambda_{n}\right) U_{n, 1} y_{n} \\
& =\lambda_{n} f_{n}\left(y_{n}\right)+\left(1-\lambda_{n}\right)\left(\left(1-\gamma_{1}\right) y_{n}+\gamma_{1} S_{n} y_{n}\right)
\end{aligned}
$$

for every $n \in \mathbb{N}$. It is known that

$$
\operatorname{Fix}\left(S_{n}\right)=\operatorname{Fix}\left(U_{n, 1}\right)=\bigcap_{k=1}^{n} \operatorname{Fix}\left(T_{k}\right)
$$

by [23, Lemma 3.2]; see also [9, Lemma 4.2]. Hence we have

$$
\bigcap_{n=1}^{\infty} \operatorname{Fix}\left(S_{n}\right)=\bigcap_{n=1}^{\infty} \operatorname{Fix}\left(U_{n, 1}\right)=\bigcap_{n=1}^{\infty} \bigcap_{k=1}^{n} \operatorname{Fix}\left(T_{k}\right)=F
$$

and thus

$$
f_{n}(z)=(I-A) U_{n, 1} z=(I-A) z
$$

for all $z \in F$. Therefore, $\left\{f_{n}\right\}$ is stable on $F$. Since $U_{n, 1}$ is nonexpansive, $f_{n}$ is a $\theta$-contraction by Lemma 2.4, where $\theta=\sqrt{1-2 \kappa+\eta^{2}}$. It is also known that $\left\{S_{n}\right\}$ satisfies the conditions $(\mathrm{Z})$ and $(\mathrm{R})$; see $[3,5,9,11]$. Therefore, Theorem 3.6 implies that $\left\{y_{n}\right\}$ converges strongly to $w=P_{F}\left(f_{1}(w)\right)=P_{F}(I-A) w$, which is the unique solution of Problem 4.1 by Lemma 2.4. 


\section{Zero point problems and fixed point problems}

Motivated by Ceng, Petruşel, and Yao [13], we consider the problem of finding a common solution of the zero point problem for a maximal monotone operator and the fixed point problems for nonexpansive mappings. Then, by using Theorem 3.6, we prove the following strong convergence theorem, which is a generalization of [13, Theorem 3.1]; see Remark 5.2 below.

Theorem 5.1. Let $\mathrm{H}$ be a Hilbert space, $\mathrm{C}$ a nonempty closed convex subset of $\mathrm{H},\left\{\mathrm{T}_{\mathrm{n}}\right\}$ a sequence of nonexpansive self-mappings of $\mathrm{C}, \mathrm{A} \subset \mathrm{H} \times \mathrm{H}$ a maximal monotone operator with $\operatorname{dom}(A) \subset \mathrm{C}$, $\theta$ a nonnegative real number with $\theta<1$, and $f$ a $\theta$-contraction on $C$. Let $\left\{\alpha_{n}\right\}$, $\left\{\beta_{n}\right\}$, and $\left\{\gamma_{n}\right\}$ be sequences in $[0,1)$ such that $\alpha_{n} \rightarrow 0, \sum_{n=1}^{\infty} \alpha_{n}=\infty, 0<\liminf _{n \rightarrow \infty} \beta_{n} \leq \sup _{n} \beta_{n}<1$, $\alpha_{n}+\beta_{n} \leq 1$ for every $n \in \mathbb{N}, 0<\liminf _{n \rightarrow \infty} \gamma_{n} \leq \sup _{n} \gamma_{n}<1$, and $\gamma_{n+1}-\gamma_{n} \rightarrow 0$. Let $\left\{\rho_{n}\right\}$ be a sequnece of positive real numbers such that $\inf _{n} \rho_{n}>0$ and $\rho_{n+1}-\rho_{n} \rightarrow 0$. Suppose that $\mathrm{F}=\bigcap_{\mathrm{n}=1}^{\infty} \operatorname{Fix}\left(\mathrm{T}_{\mathrm{n}}\right) \cap \mathrm{A}^{-1} 0$ is nonempty and

$$
\lim _{n \rightarrow \infty} \sup _{y \in D}\left\|T_{n} y-T_{m} T_{n} y\right\|=0 \text { and } \lim _{n \rightarrow \infty} \sup _{y \in D}\left\|T_{n+1} y-T_{m} T_{n} y\right\|=0
$$

for any $\mathrm{m} \in \mathbb{N}$ and nonempty bounded subset $\mathrm{D}$ of $\mathrm{C}$. Let $\mathrm{y}$ be a point in $\mathrm{C}$ and $\left\{\mathrm{y}_{\mathrm{n}}\right\}$ a sequence defined by $\mathrm{y}_{1}=\mathrm{y}$ and

$$
y_{n+1}=\alpha_{n} f\left(V_{n} x_{n}\right)+\left(1-\alpha_{n}-\beta_{n}\right) x_{n}+\beta_{n} T_{n} V_{n} x_{n}
$$

for $\mathrm{n} \in \mathbb{N}$, where $\mathrm{V}_{\mathrm{n}}=\gamma_{\mathrm{n}} \mathrm{I}+\left(1-\gamma_{\mathrm{n}}\right) \mathrm{T}_{\mathrm{n}} \mathrm{J}_{\rho_{\mathrm{n}}}$ and $\mathrm{J}_{\rho_{\mathrm{n}}}$ is the resolvent of $\mathrm{A}$. Then $\left\{\mathrm{y}_{\mathrm{n}}\right\}$ converges strongly to the unique fixed point of $\mathrm{P}_{\mathrm{F}} \circ \mathrm{f}$.

Proof. Since $\gamma_{n} \neq 1$ and $\operatorname{Fix}\left(T_{n}\right) \cap \operatorname{Fix}\left(J_{\rho_{n}}\right)=\operatorname{Fix}\left(T_{n}\right) \cap A^{-1} 0$ is nonempty, it follows from [8, Corollary 3.9] and [9, Corollary 3.6] that

$$
\operatorname{Fix}\left(V_{n}\right)=\operatorname{Fix}\left(T_{n} J_{\rho_{n}}\right)=\operatorname{Fix}\left(T_{n}\right) \cap \operatorname{Fix}\left(J_{\rho_{n}}\right)=\operatorname{Fix}\left(T_{n}\right) \cap A^{-1} 0
$$

and

$$
\operatorname{Fix}\left(T_{n} V_{n}\right)=\operatorname{Fix}\left(T_{n}\right) \cap \operatorname{Fix}\left(V_{n}\right)=\operatorname{Fix}\left(V_{n}\right)
$$

for every $n \in \mathbb{N}$. Therefore, we have

$$
\bigcap_{n=1}^{\infty} \operatorname{Fix}\left(T_{n} V_{n}\right)=\bigcap_{n=1}^{\infty} \operatorname{Fix}\left(V_{n}\right)=\bigcap_{n=1}^{\infty} \operatorname{Fix}\left(T_{n}\right) \cap A^{-1} 0=F \neq \emptyset
$$

It is clear that each $V_{n}$ is nonexpansive and thus $f \circ V_{n}$ is a $\theta$-contraction for every $n \in \mathbb{N}$. Since $f\left(V_{n} z\right)=f(z)$ for all $z \in F$ by (5.3), we see that $\left\{f \circ V_{n}\right\}$ is stable on $F$.

We next show that $\left\{T_{n} V_{n}\right\}$ satisfies the condition $(R)$. Let $D$ be a nonempty bounded subset of C. By (5.1), we have

$$
\lim _{n \rightarrow \infty} \sup _{y \in D}\left\|T_{n+1} y-T_{n} y\right\| \leq \lim _{n \rightarrow \infty} \sup _{y \in D}\left\|T_{n+1} y-T_{1} T_{n} y\right\|+\lim _{n \rightarrow \infty} \sup _{y \in D}\left\|T_{1} T_{n} y-T_{n} y\right\|=0
$$


and hence $\left\{T_{n}\right\}$ satisfies the condition (R). Since $\left\{J_{\rho_{n}}\right\}$ satisfies the condition (R) by [5, Example 4.2], Lemma 2.2 shows that $\left\{T_{n} J_{\rho_{n}}\right\}$ satisfies the condition (R). Thus Lemma 2.3 implies that $\left\{V_{n}\right\}$ satisfies the condition (R). Therefore, it follows from Lemma 2.2 that $\left\{T_{n} V_{n}\right\}$ satisfies the condition (R).

We next show that $\left\{T_{n} V_{n}\right\}$ satisfies the condition (Z). Let $\left\{x_{n}\right\}$ be a bounded sequence in $C$ such that $x_{n}-T_{n} V_{n} x_{n} \rightarrow 0$ and $\left\{x_{n_{i}}\right\}$ a subsequence of $\left\{x_{n}\right\}$ such that $x_{n_{i}} \rightarrow z$. It is enough to show that $z \in F$. It follows from [8, Theorem 3.10] that $x_{n}-T_{n} x_{n} \rightarrow 0$ and $x_{n}-V_{n} x_{n} \rightarrow 0$. Let $\mathrm{D}$ be a nonempty bounded subset of $\mathrm{C}$ such that $x_{n} \in \mathrm{D}$ for all $n \in \mathbb{N}$. For fixed $m \in \mathbb{N}$, it follows from (5.1) and $x_{n}-T_{n} x_{n} \rightarrow 0$ that

$$
\begin{aligned}
\left\|x_{n}-T_{m} x_{n}\right\| & \leq\left\|x_{n}-T_{n} x_{n}\right\|+\left\|T_{n} x_{n}-T_{m} T_{n} x_{n}\right\|+\left\|T_{m} T_{n} x_{n}-T_{m} x_{n}\right\| \\
& \leq 2\left\|x_{n}-T_{n} x_{n}\right\|+\sup _{y \in D}\left\|T_{n} y-T_{m} T_{n} y\right\| \rightarrow 0
\end{aligned}
$$

as $\mathrm{n} \rightarrow 0$. Thus, by the demiclosedness [15, p.109] of $\mathrm{I}-\mathrm{T}_{\mathrm{m}}, z \in \operatorname{Fix}\left(\mathrm{T}_{\mathrm{m}}\right)$ and hence $z \in$ $\bigcap_{n=1}^{\infty} \operatorname{Fix}\left(T_{n}\right)$. On the other hand, $x_{n}-V_{n} x_{n} \rightarrow 0$ and [9, Corollary 3.2] imply that $x_{n}-T_{n} J_{\rho_{n}} x_{n} \rightarrow$ 0 and hence $x_{n}-J_{\rho_{n}} x_{n} \rightarrow 0$ by [8, Theorem 3.10]. Thus $z \in A^{-1} 0$ because $\left\{J_{\rho_{n}}\right\}$ satisfies the condition (Z); see [8, Lemma 5.1], [10, Lemma 2.1], and [12, Lemma 2.4]. Consequently, we conclude that $z \in \mathrm{F}$.

Finally, by assumption, it is obvious that

$$
y_{n+1}=\alpha_{n} f\left(V_{n} x_{n}\right)+\left(1-\alpha_{n}\right)\left(\left(1-\frac{\beta_{n}}{1-\alpha_{n}}\right) x_{n}+\frac{\beta_{n}}{1-\alpha_{n}} T_{n} V_{n} x_{n}\right)
$$

for every $n \in \mathbb{N}$ and

$$
0<\liminf _{n \rightarrow \infty} \frac{\beta_{n}}{1-\alpha_{n}} \leq \limsup _{n \rightarrow \infty} \frac{\beta_{n}}{1-\alpha_{n}}<1 .
$$

Thus Theorem 3.6 implies the conclusion.

Remark 5.2. Ceng, Petruşel, and Yao [13] considered an equilibrium problem for a real-valued function $\phi$ defined on $\mathrm{C} \times \mathrm{C}$ and they adopted the resolvent of $\phi$ in [13, Theorem 3.1]. According to [6], such an equilibrium problem can be regarded as a zero point problem for a maximal monotone operator $\mathrm{A} \subset \mathrm{H} \times \mathrm{H}$ and we know that the resolvent $\phi$ is equivalent to that of $\mathrm{A}$. Thus Theorem 5.1 is a generalization of [13, Theorem 3.1].

Acknowledgment. The authors are supported by Grant-in-Aid for Scientific Research No. 22540175 from Japan Society for the Promotion of Science.

Received: March 2012. Accepted: March 2013. 


\section{References}

[1] K. Aoyama, An iterative method for fixed point problems for sequences of nonexpansive mappings, Fixed Point theory and its Applications, Yokohama Publ., Yokohama, 2010, pp. 1-7.

[2] __ An iterative method for a variational inequality problem over the common fixed point set of nonexpansive mappings, Nonlinear analysis and convex analysis, Yokohama Publ., Yokohama, 2010, pp. 21-28.

[3] _ Asymptotic fixed points of sequences of quasi-nonexpansive type mappings, Banach and function spaces III, Yokohama Publ., Yokohama, 2011, pp. 343-350.

[4] K. Aoyama and Y. Kimura, A note on the hybrid steepest descent methods, available at arXiv: 1101.0881 [math.FA].

[5] _ Strong convergence theorems for strongly nonexpansive sequences, Appl. Math. Comput. 217 (2011), 7537-7545.

[6] K. Aoyama, Y. Kimura, and W. Takahashi, Maximal monotone operators and maximal monotone functions for equilibrium problems, J. Convex Anal. 15 (2008), 395-409.

[7] K. Aoyama, Y. Kimura, W. Takahashi, and M. Toyoda, Approximation of common fixed points of a countable family of nonexpansive mappings in a Banach space, Nonlinear Anal. 67 (2007), 2350-2360.

[8] _ On a strongly nonexpansive sequence in Hilbert spaces, J. Nonlinear Convex Anal. 8 (2007), 471-489.

[9] _ Strongly nonexpansive sequences and their applications in Banach spaces, Fixed Point theory and its Applications, Yokohama Publ., Yokohama, 2008, pp. 1-18.

[10] K. Aoyama, F. Kohsaka, and W. Takahashi, Shrinking projection methods for firmly nonexpansive mappings, Nonlinear Anal. 71 (2009), e1626-e1632.

[11] _ Strongly relatively nonexpansive sequences in Banach spaces and applications, J. Fixed Point Theory Appl. 5 (2009), 201-224.

$[12]$, Strong convergence theorems for a family of mappings of type $(P)$ and applications, Nonlinear analysis and optimization, Yokohama Publ., Yokohama, 2009, pp. 1-17.

[13] L. C. Ceng, A. Petruşel, and J. C. Yao, Iterative approaches to solving equilibrium problems and fixed point problems of infinitely many nonexpansive mappings, J. Optim. Theory Appl. 143 (2009), 37-58.

[14] C. Chidume, Geometric properties of Banach spaces and nonlinear iterations, Lecture Notes in Mathematics, vol. 1965, Springer-Verlag London Ltd., London, 2009.

[15] K. Goebel and W. A. Kirk, Topics in metric fixed point theory, Cambridge Studies in Advanced Mathematics, vol. 28, Cambridge University Press, Cambridge, 1990.

[16] B. Halpern, Fixed points of nonexpanding maps, Bull. Amer. Math. Soc. 73 (1967), 957-961.

[17] S. Iemoto and W. Takahashi, Strong convergence theorems by a hybrid steepest descent method for countable nonexpansive mappings in Hilbert spaces, Sci. Math. Jpn. 69 (2009), 227-240.

[18] L. S. Liu, Ishikawa and Mann iterative process with errors for nonlinear strongly accretive mappings in Banach spaces, J. Math. Anal. Appl. 194 (1995), 114-125. 
[19] A. Moudafi, Viscosity approximation methods for fixed-points problems, J. Math. Anal. Appl. 241 (2000), 46-55.

[20] N. Shioji and Wataru Takahashi, Strong convergence of approximated sequences for nonexpansive mappings in Banach spaces, Proc. Amer. Math. Soc. 125 (1997), 3641-3645.

[21] T. Suzuki, Moudafi's viscosity approximations with Meir-Keeler contractions, J. Math. Anal. Appl. 325 (2007), 342-352.

[22] W. Takahashi, Introduction to nonlinear and convex analysis, Yokohama Publ., Yokohama, 2009.

[23] W. Takahashi and K. Shimoji, Convergence theorems for nonexpansive mappings and feasibility problems, Math. Comput. Modelling 32 (2000), 1463-1471.

[24] X. Weng, Fixed point iteration for local strictly pseudo-contractive mapping, Proc. Amer. Math. Soc. 113 (1991), 727-731.

[25] R. Wittmann, Approximation of fixed points of nonexpansive mappings, Arch. Math. (Basel) 58 (1992), 486-491.

[26] H. K. Xu, Another control condition in an iterative method for nonexpansive mappings, Bull. Austral. Math. Soc. 65 (2002), 109-113.

[27] - Iterative algorithms for nonlinear operators, J. London Math. Soc. (2) 66 (2002), $240-256$.

[28] — Viscosity approximation methods for nonexpansive mappings, J. Math. Anal. Appl. 298 (2004), 279-291.

[29] H. K. Xu and T. H. Kim, Convergence of hybrid steepest-descent methods for variational inequalities, J. Optim. Theory Appl. 119 (2003), 185-201.

[30] I. Yamada, The hybrid steepest descent method for the variational inequality problem over the intersection of fixed point sets of nonexpansive mappings, Inherently parallel algorithms in feasibility and optimization their applications (Haifa, 2000), Stud. Comput. Math., vol. 8, North-Holland, Amsterdam, 2001, pp. 473-504.

[31] I. Yamada and N. Ogura, Hybrid steepest descent method for variational inequality problem over the fixed point set of certain quasi-nonexpansive mappings, Numer. Funct. Anal. Optim. 25 (2004), 619-655. 